\title{
O efeito do vento nas quedas de árvores em Piracicaba/SP
}

\author{
Wind effect on fallen trees in Piracicaba/SP
}

\section{Flávio Henrique Mendes ${ }^{1}$, Jefferson Lordello Polizel $^{2}$ e Demóstenes Ferreira da Silva Filho ${ }^{3}$}

${ }^{1}$ Mestrando em Recursos Florestais, Departamento de Ciências Florestais, Universidade de São Paulo, Escola Superior de Agricultura “Luiz de Queiroz", Piracicaba, Brasil friquemendes@usp.br

${ }^{2}$ Doutor em Geografia Física, Departamento de Ciências Florestais, Universidade de São Paulo, Escola Superior de Agricultura "Luiz de Queiroz", Piracicaba, Brasil jlpolize@usp.br

${ }^{3}$ Professor Doutor, Departamento de Ciências Florestais, Universidade de São Paulo, Escola Superior de Agricultura "Luiz de Queiroz", Piracicaba, Brasil dfilho@usp.br

\begin{abstract}
Resumo
O objetivo foi estudar o comportamento das quedas de árvores no município de Piracicaba/SP, Brasil, com atenção especial ao regime de ventos. O Corpo de Bombeiro forneceu um banco de dados de quedas contendo 275 casos, de 3 de janeiro de 2011 a 24 de maio de 2014, com a respectiva localização, os quais foram plotados em SIG. O efeito da urbanização teve grande importância nas quedas, cuja região central concentrou a maior parte, 36,7\%. As estações da primavera e verão somaram $78,0 \%$ das quedas, que correspondem, respectivamente, aos períodos de ventos e chuvas mais intensos. O período de retorno esperado para ventos acima de $75 \mathrm{~km} \mathrm{h-1,} \mathrm{classificados} \mathrm{como}$ temporais na Escala de vento de Beaufort, foi de 2,8 eventos por ano. As espécies de maior vulnerabilidade à queda foram Pachira aquatica Aubl. (monguba), Handroanthus sp. (ipê roxo) e Tipuana tipu (Benth.) Kuntze (tipuana), caracterizando oportunidades de manejo específicas. Enquanto verificou-se o predomínio de ventos alísios de sudeste, pertencentes ao quarto quadrante, a direção das rajadas teve maior variação e, com predomínio de ventos de sudeste, é recomendável instalações de parques industriais nas zonas norte, noroeste e oeste, visto a importância em evitar que poluentes adentrem a cidade.
\end{abstract}

Palavras-chave: Regime de ventos; Urbanização; Vulnerabilidade de espécies.

\begin{abstract}
The aimed was study the behavior of fallen trees in Piracicaba city, São Paulo state, Brazil, with special attention at the wind regime. The Fire Department provided a falls database, with 275 cases, from January 3rd, 2011 to May 24th, 2014, with their respective location, that were plotted on GIS. The urbanization effect had great importance on the falls, where the central region concentrated the most part, $36.7 \%$. The spring and summer seasons amounted to $78.0 \%$ of falls, that correspond, in this order, to the periods of more intense winds and rains. The payback period expected to winds above $75 \mathrm{~km} \mathrm{h-1,} \mathrm{classified} \mathrm{as} \mathrm{storms} \mathrm{in} \mathrm{the} \mathrm{Beaufort} \mathrm{Wind} \mathrm{Scale,} \mathrm{was} 2.8$ events per year. The species such as greater vulnerability to the fall were Pachira aquatica Aubl. (Guiana Chestnut), Handroanthus sp. (Purple Ipe) and Tipuana tipu (Benth.) Kuntze (Tipuana), requiring specific oportunities of management. While there was a predominance of trade winds from the Southeast, belonging to the fourth quadrant, the gusts' direction had greater variation and, since the predominance of Southeast winds, it is recommended to spot industrial parks at North, Northwest and West zones, given the importance to prevent pollutants enter into the city.
\end{abstract}

Keywords: Wind regime; Urbanization; Vulnerability of species. 


\section{Introdução}

São muitos os benefícios provenientes da arborização de vias públicas (SHASHUA-BAR; HOFFMAN, 2000; DOBBERT et al., 2014) entretanto, as árvores podem estar vulneráveis a sofrer alavancas e cair, tendo o vento como um dos agentes agravantes (MATTHECK; BRELOER, 1997).

Segundo o Dicionário do Aurélio, entende-se por "vulnerável" como "o lado fraco de uma questão ou do ponto por onde alguém pode ser ferido ou atacado".

$\mathrm{O}$ vento origina-se por diferenças na pressão atmosférica, com deslocamento de ar de zonas de maior pressão para as de menor pressão, ao criar diferentes velocidades, além da força de Coriolis, surgida devido ao movimento de rotação da Terra (BONAN, 2002).

No globo terrestre, há três tipos de correntes atmosféricas: (i) ventos alísios, entre latitudes $30^{\circ} \mathrm{N}$ e $30^{\circ} \mathrm{S}$, de fraca intensidade; (ii) ventos oestes, entre $30^{\circ}$ e $60^{\circ}$ $\mathrm{N}$ e $\mathrm{S}$, que são rápidos e (iii) ventos polares, de latitudes maiores que $60^{\circ}$, que são tempestuosos. No Brasil, predominam-se os ventos alísios, de sentido sudeste (PRATA, 2005), conforme mostra a figura 1.

Torna-se complicado prever o tempo de Piracicaba/ SP com exatidão, devido aos fluxos de massas de ar ao longo do ano. Na região sudeste, há o predomínio da Massa Tropical Atlântica (mTa) durante o verão, caracterizada como quente e úmida, originária no Atlântico Sul, enquanto que, no inverno, a Massa Polar Atlântica (mPa), fria e úmida, com origem na Antártida (Figura 2).

Em meio urbano, o vento é responsável pela dispersão de poluentes. Pesquisa feita pelo Instituto de Astronomia, Geofísica e Ciências Atmosféricas da Universidade de São
Paulo (IAG/USP) provou que a Região Metropolitana de São Paulo (capital e mais 38 municípios vizinhos) é um centro exportador de poluentes: 20 a $30 \%$ da poluição encontrada em Campinas, Tatuí e Sorocaba vêm de São Paulo, em virtude do regime dos ventos que, dependendo da intensidade, pode chegar a Bauru/SP, a $400 \mathrm{~km}$ da capital paulista. O que ameniza a situação de São Paulo é a brisa marinha do Oceano Atlântico, que circula a 500 $\mathrm{m}$ da superfície, atenuando a temperatura e dispersando poluentes. Por outro lado, Cubatão, ao pé da Serra do Mar, é responsável direto pelo ozônio encontrado no planalto paulista (FIORAVANTI, 2002).

Em microescala, o vento pode sofrer alterações devido ao processo de urbanização, por meio da rugosidade das áreas (CLEUGH; GRIMMOND, 2011), sendo esta um valor de aspereza da superfície, ou seja, alturas de massas edificadas capazes de alterar significativamente os movimentos dos deslocamentos das massas de ar (SANTOS, 2004).

Na prática, os valores de rugosidade não são calculados, por isso, utiliza-se a tabela do European Wind Atlas (TROEN; PETERSEN, 1989) (Tabela 1).

A figura 3 mostra o comportamento do vento em função de diferentes tipologias (centro urbano, subúrbio e campo aberto).

Para as quedas de árvores, Albers et al. (1992) avalia que são sete categorias responsáveis: declínio, rachaduras, problemas radiculares, fraca união de galhos, cancros, arquitetura ruim e madeira morta. De modo a garantir a integridade das raízes, os autores propõem o conceito de Critical root radius (CRR), sendo representado pela relação DAP x 1,5 e, se mais de $40 \%$ da área estiver danificada, a estabilidade fica comprometida (Figura 4).

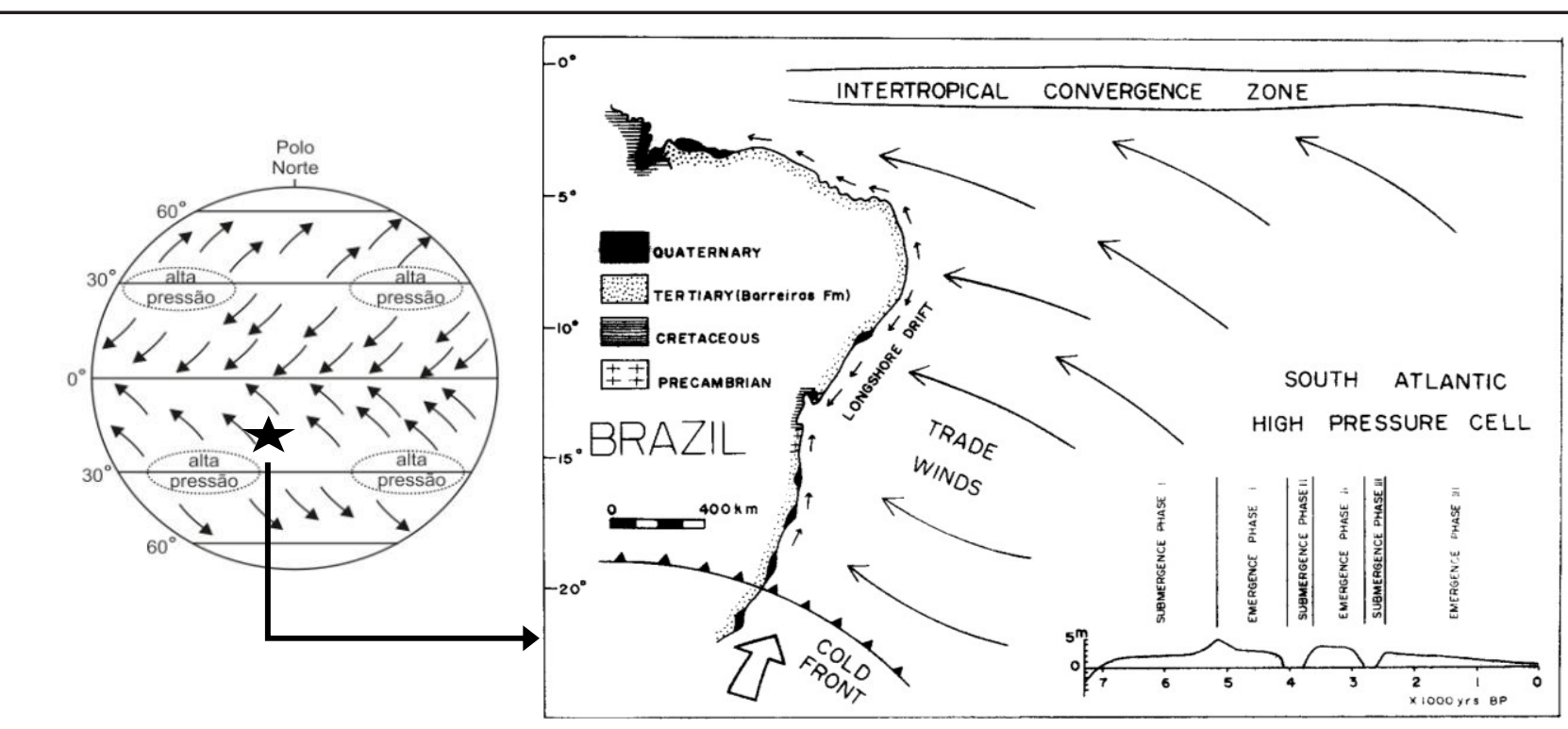

Figura 1 - Regime de ventos na Terra, com destaque para os ventos alísios de sudeste. Fonte: Adaptado de Dominguez, Bittencourt e Martin (1992) 


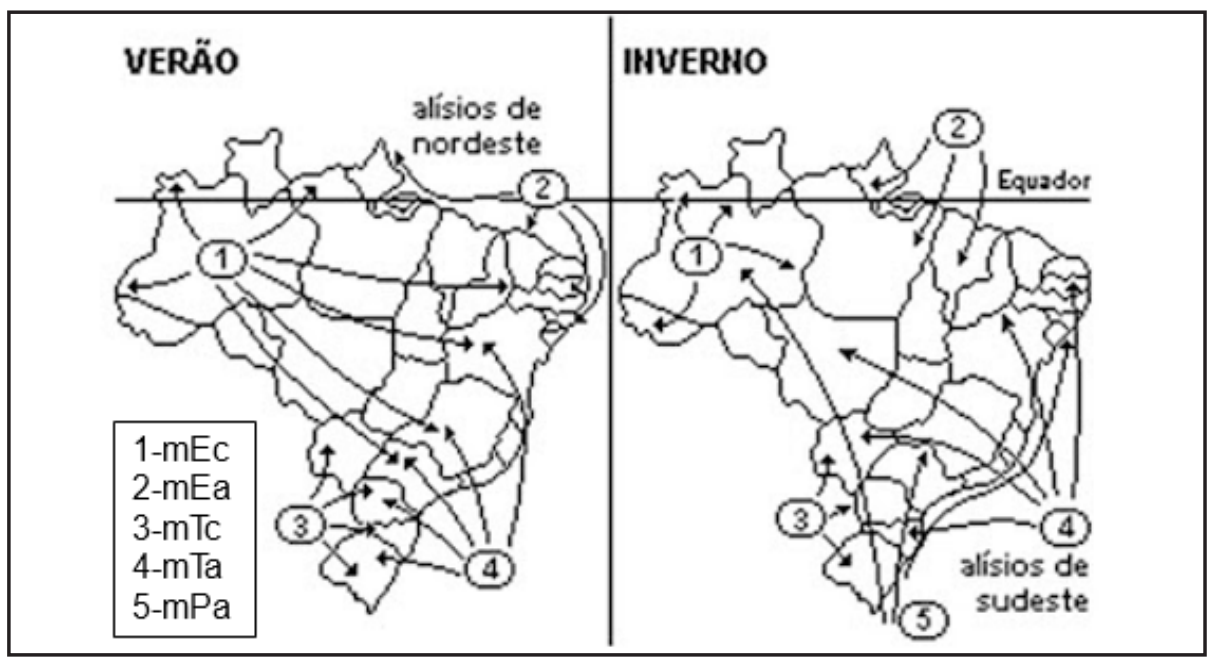

Figura 2 - Influências das massas de ar no território brasileiro. Fonte: Adaptado de Sene e Moreira (1998)

Tabela 1 - Valores de rugosidade para diferentes superfícies

\begin{tabular}{|c|c|}
\hline $\mathrm{Z} 0$ & Características do terreno \\
\hline 1,00 & Cidade \\
\hline 0,80 & Floresta \\
\hline 0,50 & Subúrbios \\
\hline 0,30 & Cinturões de árvores \\
\hline 0,20 & Árvores e arbustos \\
\hline 0,10 & Fazenda com vegetação fechada \\
\hline 0,05 & Fazendo com vegetação aberta \\
\hline 0,03 & $\begin{array}{c}\text { Fazenda com poucas árvores/ } \\
\text { edificações }\end{array}$ \\
\hline 0,02 & $\begin{array}{c}\text { Áreas de aeroportos com edificações e } \\
\text { árvores }\end{array}$ \\
\hline 0,01 & Áreas de pistas de aeroporto \\
\hline 0,008 & Pasto \\
\hline 0,005 & Solo arado \\
\hline 0,001 & Neve \\
\hline 0,0003 & Areia \\
\hline 0,0001 & Água (lagos, rios e oceanos) \\
\hline
\end{tabular}

Fonte: Adaptado de Troen e Petersen (1998)

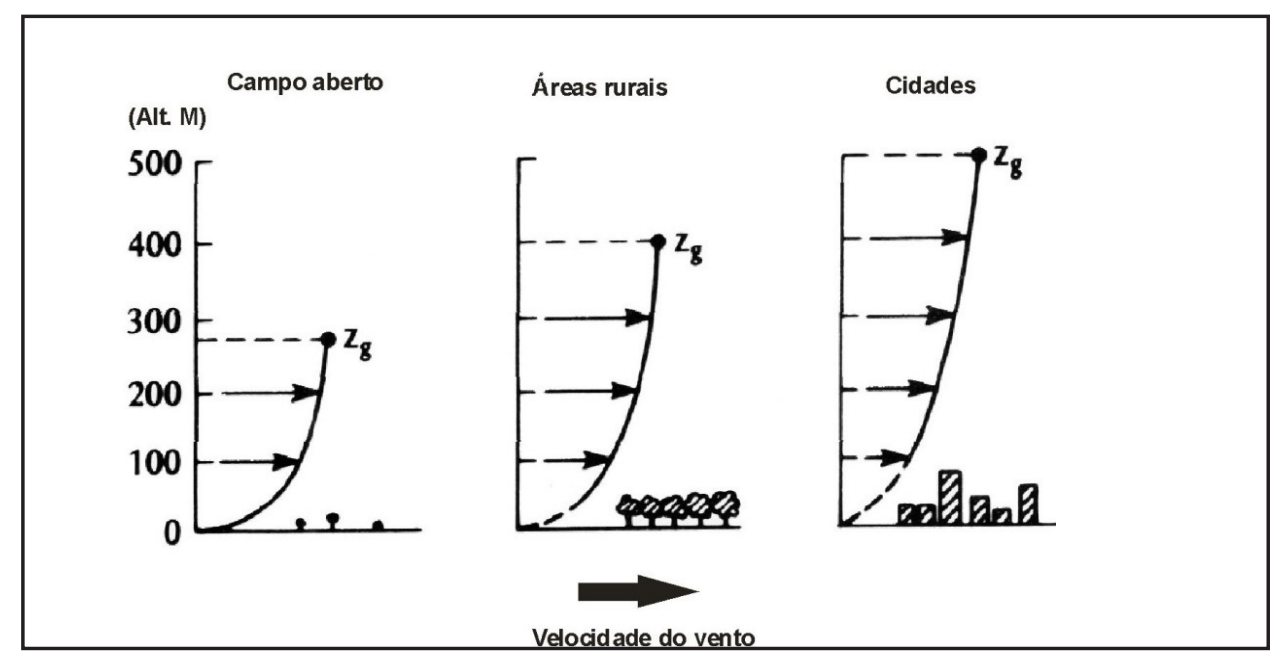

Figura 3 - Diminuição na velocidade do vento influenciada pela variação da rugosidade do terreno. Fonte: Adaptado de Oke (1987) 


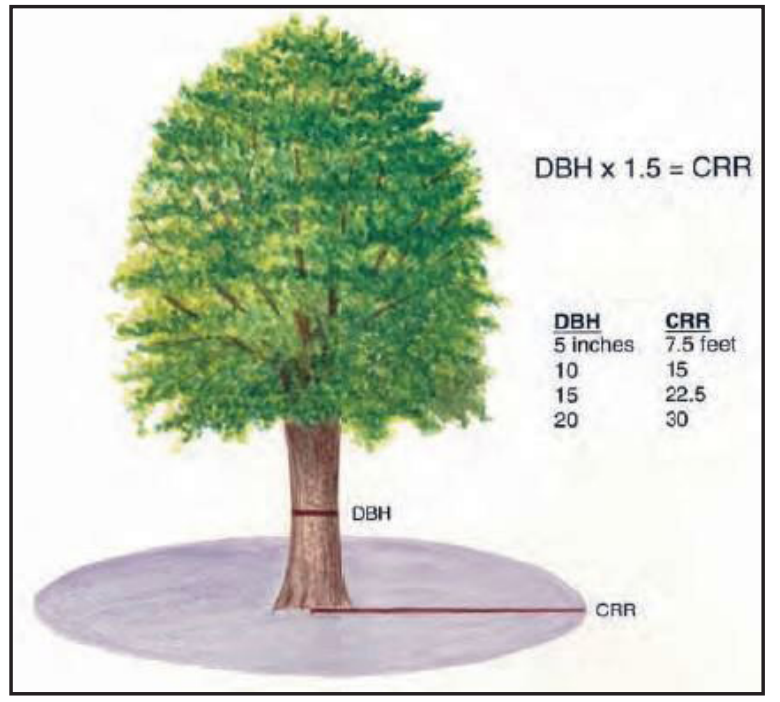

Figura 4 - Representação da área crítica para preservação da integridade das raízes. Fonte: Albers et al. (1992)

Seitz (1995) correlaciona diretamente espécie florestal e fungos degradadores de madeira, responsáveis pela quebra, cujas intempéries (chuva, vento, etc.) intensificam o processo, exceto em condições de abrigo e ambientes secos, na qual os galhos podem permanecer conectados por anos. Podas verdes capazes de desequilibrar a copa devem ser evitadas, visto que os brotos epicórmicos (sem ligação com a parte central da árvore), são frágeis à quebra.

Mattheck e Breloer (1997), especialistas em biomecânica, relataram os esforços a que as árvores são expostas, como: tração, compressão, cisalhamento e momentos de flexão e torção. Com o intuito de evitar o tombamento, criam tensões internas que alteram forma, tamanho e estrutura, evento denominado crescimento adaptado.

Mattheck (2007) avaliou o coeficiente de esbeltez (slenderness) como outro fator crítico para a queda da árvore. Esse índice pode ser obtido dividindo-se altura (m) pelo diâmetro (cm), ou seja, H/D e, se for maior que 50, a árvore fica vulnerável, assim como cavidades internas superiores a dois terços (Figura 5).

O objetivo consistiu em avaliar o comportamento das quedas de árvores no município de Piracicaba/SP.

\section{Materiais e métodos}

\section{Área de estudo}

A pesquisa teve como delimitação os limites urbanos do município de Piracicaba/SP, disponibilizados pelo IPPLAP (Instituto de Pesquisas e Planejamento de Piracicaba), em 2010. A cidade dista $164 \mathrm{~km}$ da capital do estado, com coordenadas geográficas $22^{\circ} 42^{\prime} 30^{\prime \prime} \mathrm{S}$ e $47^{\circ} 38^{\prime} 00^{\prime \prime} \mathrm{W}$, clima do tipo Cwa, conforme classificação de Köppen, a $546 \mathrm{~m}$ de altitude e $1328 \mathrm{~mm}$ de pluviosidade anual, cuja vegetação predominante é a floresta estacional semidecidual, inserida no domínio da Depressão Periférica Paulista, região rebaixada por erosão, entre as terras altas do Planalto Atlântico e as escarpas elevadas das cuestas basálticas do planalto Ocidental (OLIVEIRA; PRADO, 1989).

\section{Banco de dados}

Obteve-se com o $16^{\circ}$ Grupamento do Corpo de Bombeiros de Piracicaba/SP um banco de dados organizado das quedas de árvores no período de 3 de janeiro de 2011 a 24 de maio de 2014, contabilizando 3,5 anos regressos, com 275 casos, os quais continham endereço e data/hora da chamada do munícipe.

A metodologia apresenta algumas limitações:

(i) Dados anteriores a essa data, impressos em papel e não compilados, acabaram perdendo-se com o tempo e não foi possível obtê-los; hoje o banco de dados encontra-se informatizado;

(ii) Contabilizaram-se as quedas que apresentaram algum risco a pessoas ou patrimônio público;

(iii) O banco de dados não separou quedas de árvores com queda de galhos;

(iv) A hora do registro corresponde ao horário em

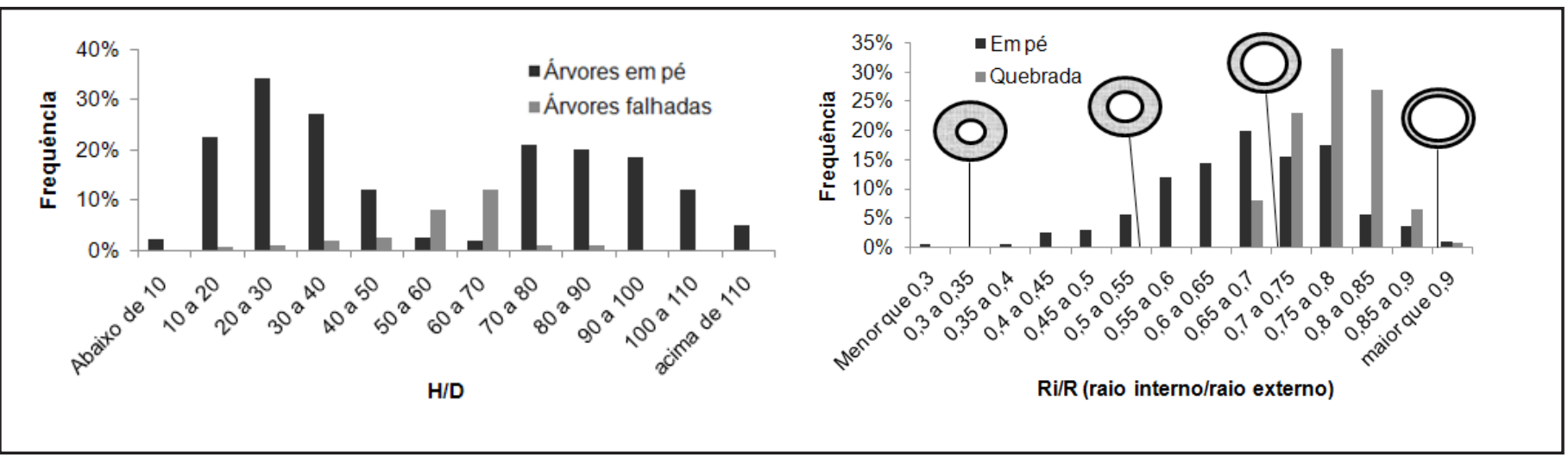

Figura 5 - Fragilidades relatadas em árvores quanto à biomecânica, sendo o coeficiente de esbeltez e a quantidade crítica de oco. Fonte: Mattheck (2007) 
que a viatura sai (atendimento da chamada) e não exatamente ao mesmo horário da queda;

(v) A SEDEMA (Secretaria de Defesa do Meio Ambiente) também possui dados de quedas de árvores (provavelmente mais que os Bombeiros), mas sem dados específicos, como o horário das ocorrências; entretanto, a Secretaria tem se esforçado para melhorias nesse sentido. Em eventos climáticos de maior urgência, ambos se unem para a mesma causa, com suporte mútuo, podendo, inclusive, oferecer apoio a cidades da região.

\section{Plotação de pontos}

Uma vez de posse das quedas com os respectivos endereços (logradouro, número, município - estado), essas foram espacializadas em SIG, por meio do site BatchGeo LLC (http://pt.batchgeo.com/), cuja versão gratuita permitiu plotar até 250 registros por vez, sendo necessário, logo, fazer esse procedimento em duas partes. Como nem todas as quedas caíram exatamente no devido ponto, fez-se a verificação uma a uma (por meio do Google Street View, imagem 2011) com os respectivos ajustes para que, em seguida, unisse num só shapefile as 275 quedas.

\section{Pressuposição de espécies}

Ainda utilizando a ferramenta Google Street View, alternando com o plugin "go2streetview", instalado no programa Quantum GIS versão 2.6, foi feita a pressuposição das espécies, quando possível (Figura 6). Destaca-se que isso foi viável em função do concílio entre as quedas

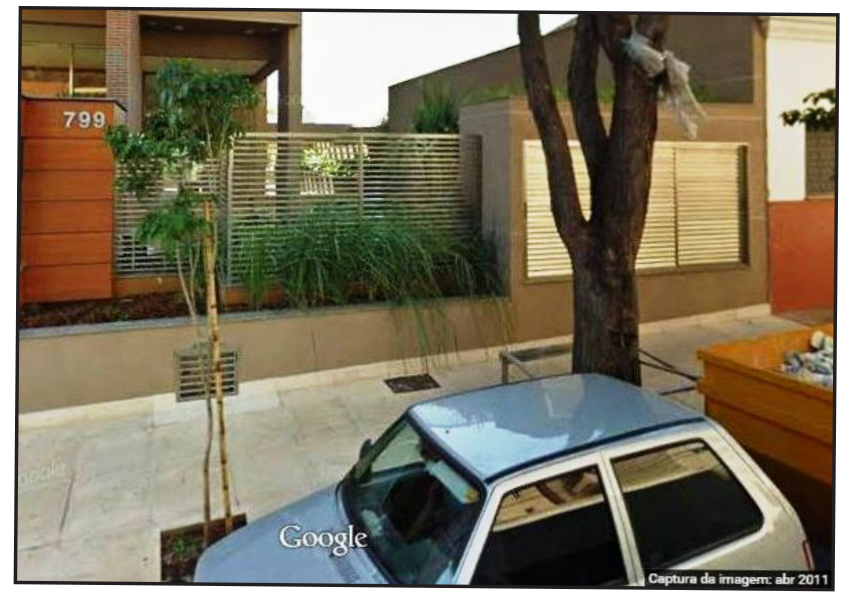

Figura 6 - Queda de árvore da espécie sibipiruna (Poincianella pluviosa (DC.) L.P. Queiroz), à direita, plotada e pressuposta, situada à Rua Floriano Peixoto, 799, no bairro Centro

dos Bombeiros (janeiro de 2011) e a imagem do nível da rua, do Google (abril de 2011). Alguns casos não foram possíveis identificar a espécie, visto que a queda foi antes de abril de 2011 ou por haver mais de uma árvore em frente ao endereço, como testadas grandes, muros de fora a fora ou locais com áreas verdes em frente.

\section{Variáveis climáticas}

As correlações com as variáveis climáticas foram feitas baseadas nos dados da Estação Meteorológica da ESALQ (http://www.leb.esalq.usp.br/posto/), sendo: (i)

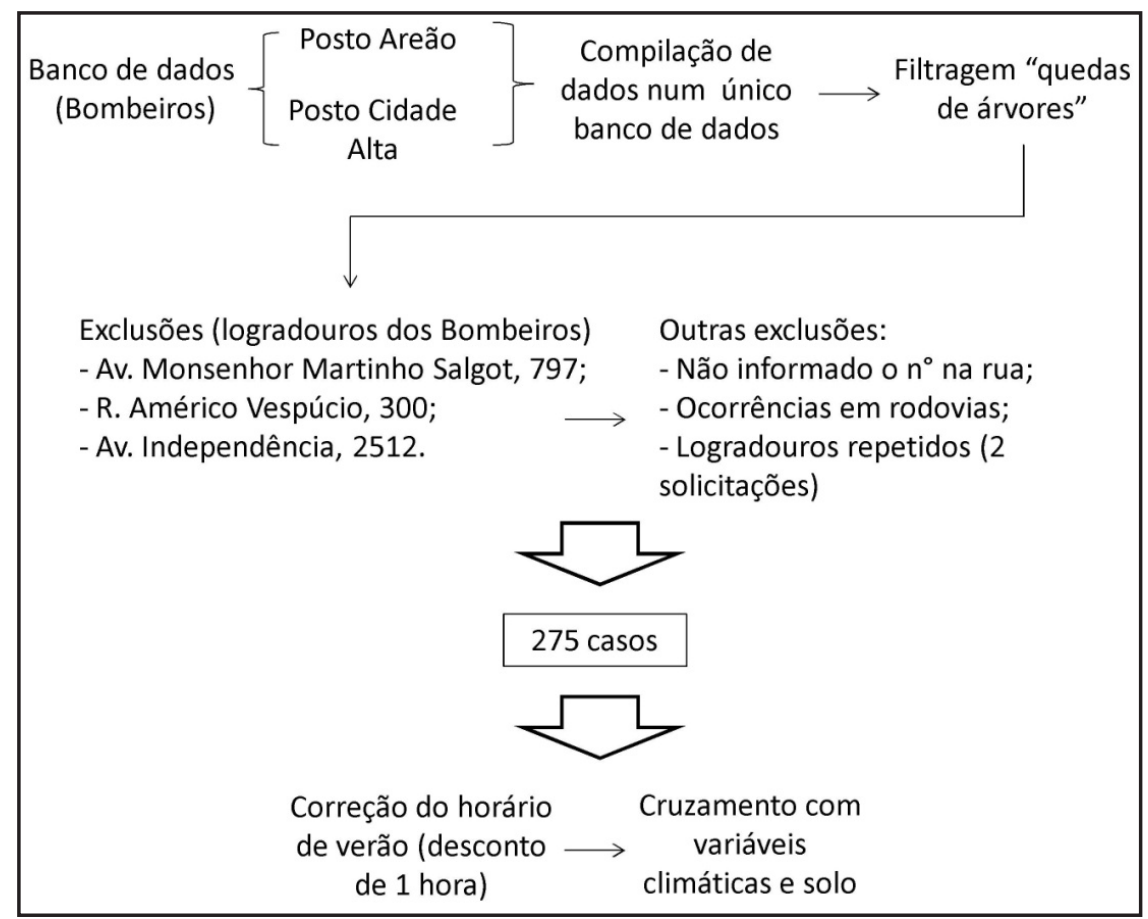

Figura 7 - Esquema de trabalho utilizado para a condução da pesquisa, desde a aquisição do banco de dados, filtragens e cruzamento com variáveis climáticas e tipo de solo 
Estação Convencional, operando desde 1917, mas somente em 1943 com medições de vento, umidade relativa do ar e pressão atmosférica e (ii) Estação Automática, desde 1997, com sensores de precipitação, temperatura, umidade, radiação, evapotranspiração, velocidade e direção do vento.

As normais climatológicas são definidas de 30 em 30 anos a partir de 1901 e, assim, sucessivamente. Entretanto, quando não se completa o período e tem-se pelo menos 10 anos, podem-se fazer as Normais Climatológicas Provisórias, conforme explicado no Documento Técnico WMO-TD / N 341, da Organização Meteorológica Mundial (OMM, 1989).

Para o estudo da direção e velocidade do vento predominante utilizou-se dados da Estação Automática (1997 a 2014), a 2 m de altura, registrados a cada 15 min., enquanto que as rajadas de vento máximas e precipitação, dados diários da Estação Convencional, a $10 \mathrm{~m}$.

É importante ressaltar que às vezes foi preciso fazer a correção para UTC - 3, em função do horário de verão, uma vez que a Estação desconsiderou o evento.

Em virtude dos dados da Estação serem disponibilizados em Dias Julianos (1 a 365 ou 366), usufruiu-se do site proposto por Telmo Ghiorzi (http://ghiorzi.org/diasjuli. htm) para converter para o calendário dia/mês/ano.

O esquema de trabalho que sintetiza a metodologia é mostrado na figura 7 .

\section{Resultados e discussão}

\section{Vento}

Um vendaval de 15 m s-1 (54 km h-1)é, normalmente, o valor utilizado como referência por seguradoras em sinistros em casos de danos ao patrimônio (CAMARGO, 2014), sendo que a direção do vento predominante pode coincidir com a direção da rajada ou não (BURGARDT; LEITE; VIRGENS FILHO, 2011), cuja queda da árvore pode ocorrer em função do trajeto por onde o vendaval passa.

Inicialmente, analisou-se a correlação da velocidade do vento entre as duas estações meteorológicas da ESALQ, a Automática $(2 \mathrm{~m})$ e a Convencional $(10 \mathrm{~m})$, para os 275 casos de quedas. $\mathrm{O}$ coeficiente de determinação $\left(\mathrm{R}^{2}=\right.$ 0,7314) mostrou tendência linear dos dados (Figura 8), ao passo que o coeficiente de correlação Pearson, que varia de -1 a 1 , na qual os extremos representam forte correlação, sendo negativa ou positiva, respectivamente, foi de 0,86, classificada como forte (DANCEY; REIDY, 2006).

O trabalho de Oliveira e Lopes (2007) verificou que as árvores começam a cair com ventos de $7 \mathrm{~m} \mathrm{~s}-1$ (a 10 m de altura); no caso, 97,1\% teve o mesmo comportamento. Para velocidades acima de 10 m s-1 (36 km h-1), $81,8 \%$ e, conforme sinistros de seguradoras (acima de $15 \mathrm{~m} \mathrm{~s}-1), 42,2 \%$ do total.

A figura 9 reflete a direção do vento predominante na região, em alusão aos ventos alísios de sudeste, de acordo com a Estação Automática, visto que a Convencional não dispunha desses dados. Nota-se que as principais direções de vento pertencem ao $4^{\circ}$ quadrante (leste, sudeste e sul), podendo-se inferir que as principais regiões no município para alocação de distritos industriais são do lado oposto, ou seja, norte, noroeste e oeste, de modo que os poluentes não adentrem a cidade.

Por meio da figura 10, fica evidente que a primavera é a estação do ano que mais venta, entretanto, é no verão que ocorrem as rajadas e temporais com maiores velocidades, com média das máximas de 11,2 m s-1.

A figura 11 faz alusão à figura 10, decomposta em direções (rumos), de acordo com as rajadas de ventos a cada 15 min. Fica claro que o rumo das rajadas teve maior variação ao longo do ano, se comparado com o predomínio dos ventos alísios de sudeste na cidade (quadrante 4).

Baseado na Escala de vento de Beaufort, que auxilia na interpretação dos dados de velocidade máxima de

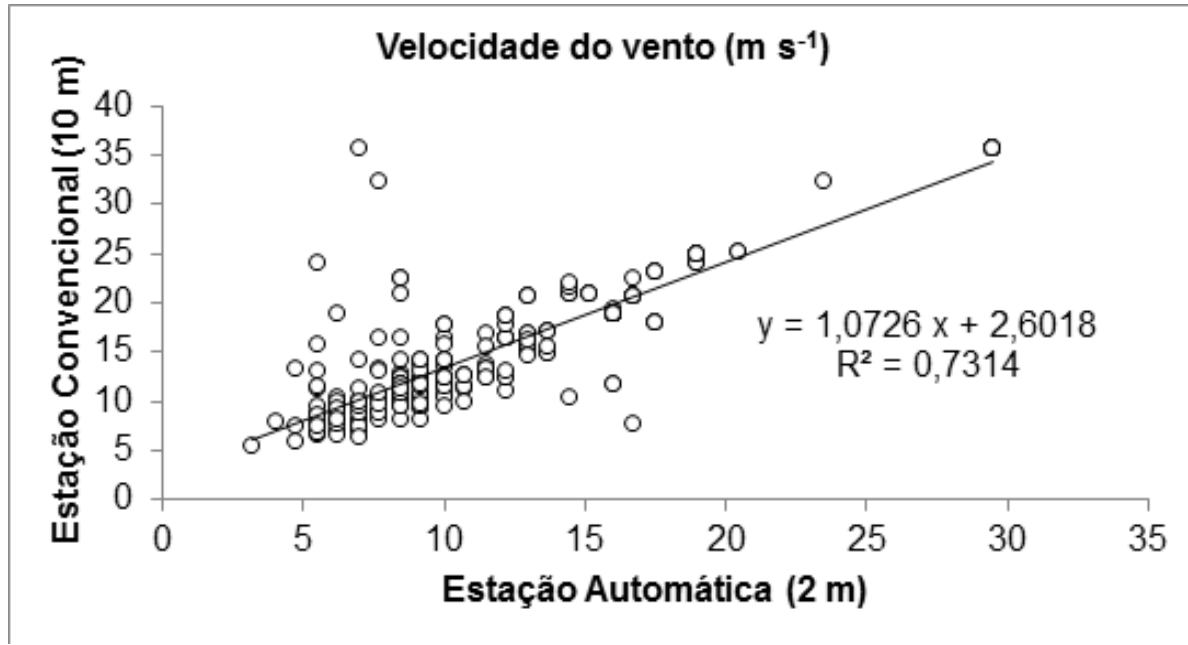

Figura 8 - Forte correlação entre a velocidade de vento aferida nas estações meteorológicas da ESALQ 


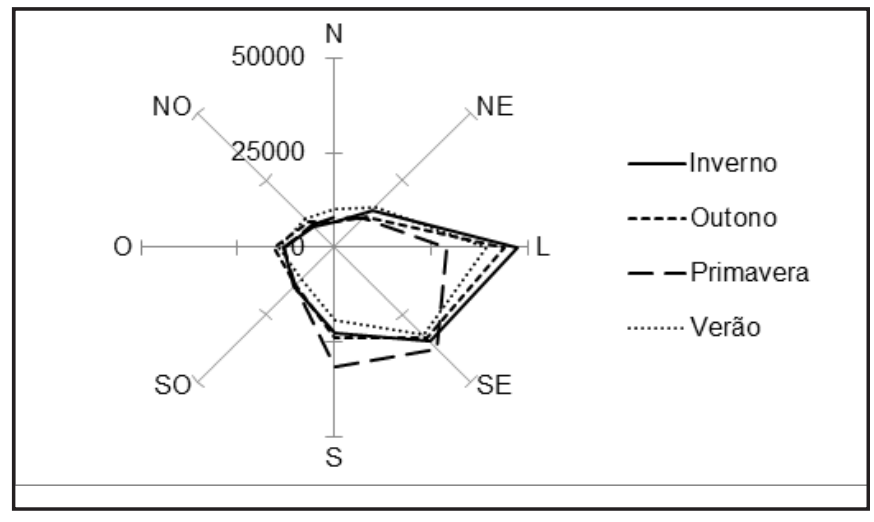

Figura 9 - Direção do vento predominante durante as quatro estações do ano

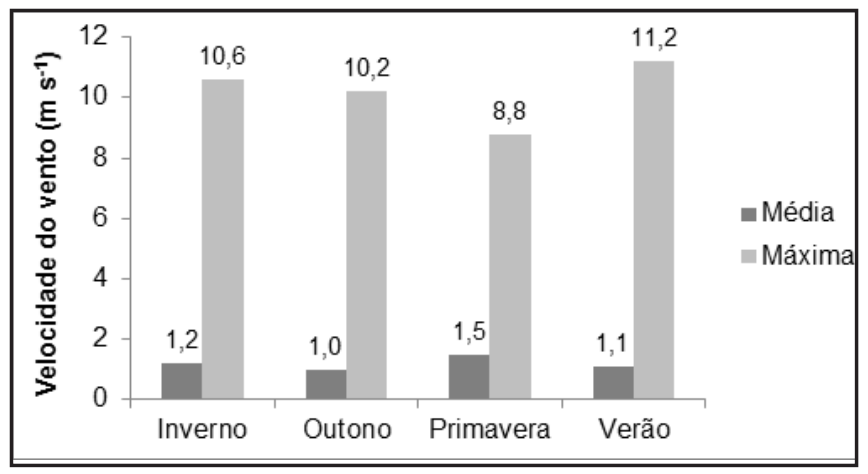

Figura 10 - Velocidade do vento: média da média e média da máxima da Estação Automática durante as quatro estações do ano

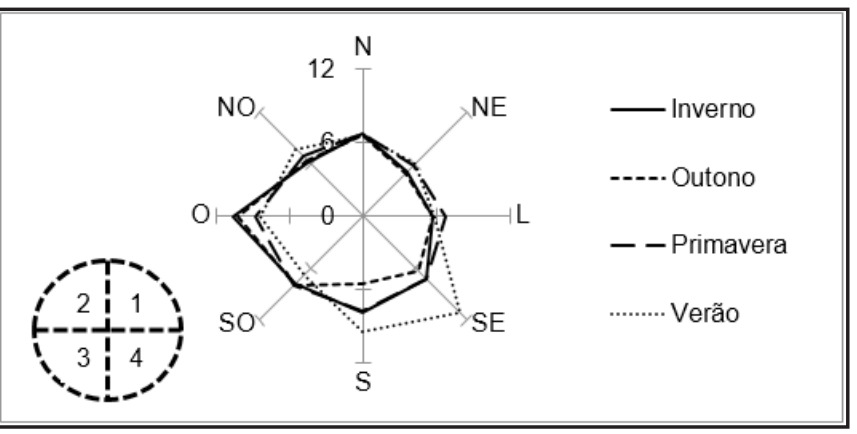

Figura 11 - Direção das rajadas de vento ao longo das estações do ano, com a respectiva média da velocidade máxima (m s-1); no canto esquerdo tem-se a numeração padrão dos 4 quadrantes

vento (rajadas), tem-se o período de retorno esperado para cada faixa correspondente (Tabela 2). Os dados foram compilados da Estação Convencional (1964 a 2014).

Verificou-se que os ventos mais frequentes enquadraram-se na faixa de 20 a $39 \mathrm{~km} \mathrm{~h}-1$, ou seja, de 5,5 a 10,8 m s-1. Para fins de comparação com o sinistro de seguradoras (15 m s-1), o período de retorno esperado para essa velocidade é de 1 a cada 19 dias. Para fenômenos naturais classificados entre "temporal" e "tornado/
Tabela 2 - Escala de vento de Beaufort e o respectivo período de retorno esperado, em dias

\begin{tabular}{c|c|c|c}
\hline Grau & Descrição & $\begin{array}{c}\text { Velocidade } \\
(\mathrm{km} \mathrm{h}-1)\end{array}$ & $\begin{array}{c}\text { Período } \\
\text { de } \\
\text { retorno } \\
\text { (dias })\end{array}$ \\
\hline 0 & Calmaria & $0-2$ & 1087,3 \\
\hline 1 & Vento Calmo & $2-6$ & 101,0 \\
\hline 2 & Brisa Amena & $7-11$ & 47,8 \\
\hline 3 & Brisa Leve & $12-19$ & 7,7 \\
\hline 4 & Brisa Moderada & $20-29$ & 3,2 \\
\hline 5 & Brisa Forte & $30-39$ & 3,4 \\
\hline 6 & Vento Forte & $40-50$ & 6,2 \\
\hline 7 & $\begin{array}{c}\text { Vento Muito } \\
\text { Forte }\end{array}$ & $51-61$ & 25,2 \\
\hline 8 & $\begin{array}{c}\text { Vento } \\
\text { Fortíssimo }\end{array}$ & $62-74$ & 55,0 \\
\hline 9 & Temporal & $75-87$ & 188,5 \\
\hline 10 & Temporal Forte & $88-101$ & 565,4 \\
\hline 11 & $\begin{array}{c}\text { Temporal } \\
\text { Muito Forte }\end{array}$ & $102-117$ & 2355,8 \\
\hline 12 & $\begin{array}{c}\text { Tornado, } \\
\text { Furacão }\end{array}$ & $>118$ & 3533,8 \\
\hline & \multicolumn{3}{|c}{}
\end{tabular}

furacão" (acima de $75 \mathrm{~km} \mathrm{h-1),} \mathrm{por} \mathrm{exemplo,} \mathrm{o} \mathrm{período}$ de retorno esperado é de 1 a cada 128,5 dias, ou seja, 2,8 eventos por ano. O principal destaque foi o dia 29 de março de 2006, quando o equipamento atingiu valor máximo de medição (44 m s-1).

É complicado estabelecer correlações com a direção do vento predominante para as árvores que caíram, uma vez que, conforme citado na metodologia, a hora do registro corresponde ao horário da chamada e não exatamente ao horário da queda.

A influência das chuvas no encharcamento do solo e a consequente queda da árvore não devem ser desprezadas: $65,5 \%$ dos casos de quedas foram em períodos de chuva nas últimas 24 horas (Figura 12), sendo que $47,6 \%$ tiveram quedas em períodos com pelo menos 5 $\mathrm{mm}$ de chuva até 1 dia antes.

\section{Locais de maior ocorrência}

De acordo com as cinco regiões geográficas da cidade, a parte central foi a que apresentou mais quedas, $36,7 \%$, seguido, respectivamente, por leste $(22,2 \%)$, norte $(20,0 \%)$, sul $(13,1 \%)$ e oeste $(8,0 \%)$. Para Mendes, Silva Filho e Lopes (2015), as sombras dos edifícios podem ser consideradas como indicativo do grau de urbanização da área. Desse modo, o centro foi a região com mais sombras (imagem do satélite WorldView-2, de 22 de abril de 2011), evidenciando o fator "urbanização" como um dos principais agravantes nas quedas das árvores (Figura 13), na qual raízes danificadas, solos compactados e canteiros estreitos são problemas comuns. 


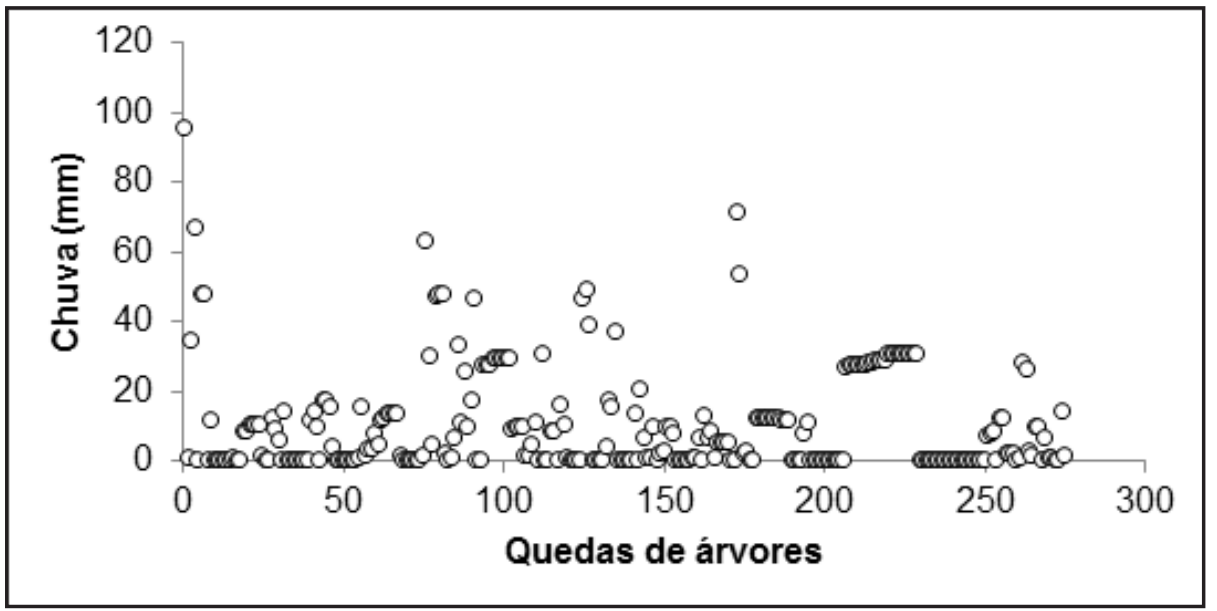

Figura 12 - Influência da pluviosidade nas quedas de árvores sendo outro fator agravante, além da velocidade dos ventos

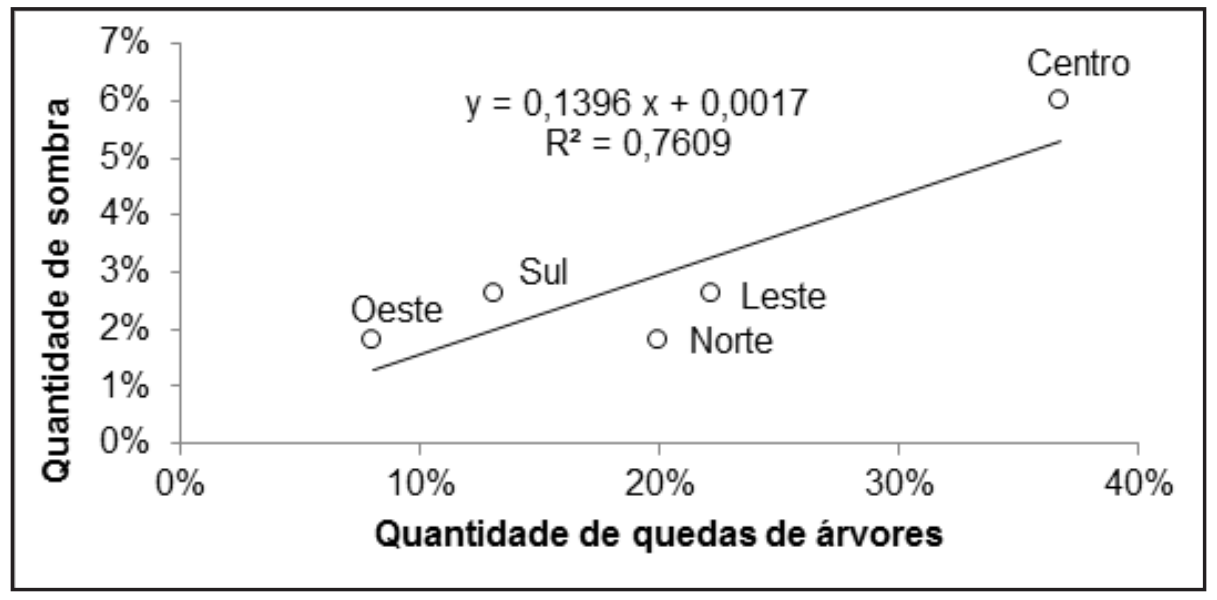

Figura 13 - Correlação entre as quedas de árvores e o grau de urbanização, representado pela quantidade de sombra dos edifícios

Ao cruzar as informações quedas de árvores com tipo de solo, sendo este proveniente do IAC (Instituto Agronômico de Campinas), verificou-se outra vez o fator "urbanização" influenciando nas quedas, onde representou $48,4 \%$, numa área do território quantificada em 29,3\% (Figura 14).

O neossolo, presente em grande quantidade no município de Piracicaba/SP (OLIVEIRA et al., 1999), possui horizonte A com menos de $40 \mathrm{~cm}$ de espessura, depositado diretamente sobre a rocha ou horizonte $\mathrm{C}$ (solo e fragmentos de rocha). Caracterizado por problemas de seca no inverno e encharcamento no verão, em relevo inclinado, o enraizamento da planta é dificultado.

As quedas concentraram-se nas estações da primavera e verão, caracterizadas pelos ventos e chuvas, nessa ordem, que representaram $78,0 \%$. Especificamente para essa análise, utilizou-se o período de 01 de janeiro de 2011 a 31 de dezembro de 2013, ou seja, exatos 3 anos completos, totalizando 250 quedas, para padronizar igual quantidade de dias em cada estação (Figura 15).

Ribeiro e Lopes (2011) viram que as ruas com orien- tações N-S registraram maiores quantidades de quedas em Lisboa, capital de Portugal, devido ao vento de rumo norte, conhecido como "nortada", comum no verão. Em função do planejamento urbano dos leitos carroçáveis, em conjunto com a direção dos ventos alísios de sudeste, predominantes na área, percebe-se que as ruas com orientação sudeste - noroeste (SE-NO) e nordeste - sudoeste (NE-SO) totalizaram $80,4 \%$ das quedas (Figura 16).

O planejamento da divisão das regiões geográficas norte, sul, leste, oeste e centro foi feito de modo adequado, seguindo a topografia do relevo, cujos limites territoriais correspondem aos topos de morro e baixadas. O modelo digital do terreno, elaborado com curvas de nível de 1 m obtidas a partir do Topodata, sob iniciativa do INPE (Instituto Nacional de Pesquisas Espaciais), revelou que as quedas nos bairros São Judas / São Dimas estão suscetíveis a ventos de maior intensidade, em virtude da altitude mais elevada do relevo (Figura 17). 


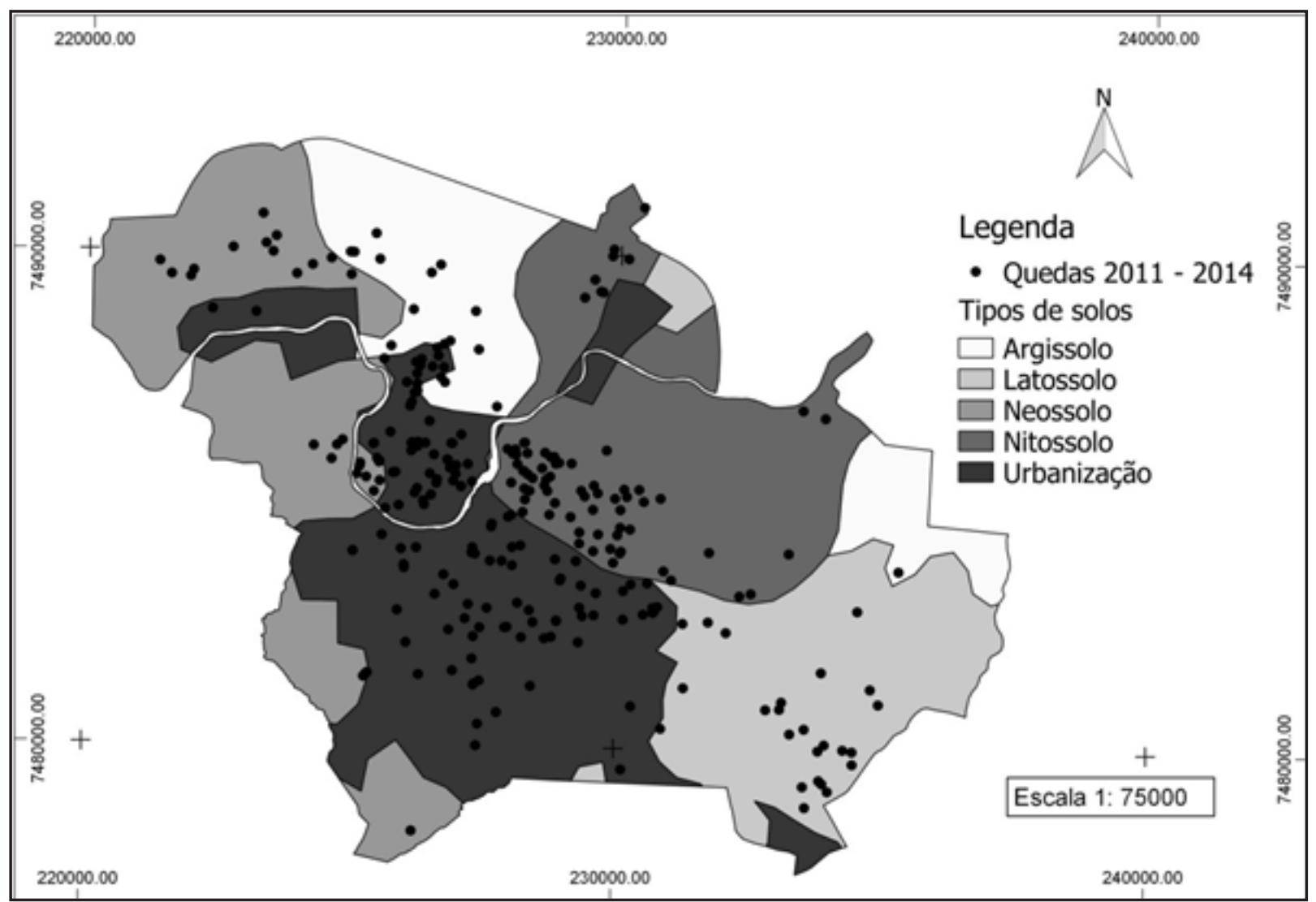

Figura 14 - Quedas de árvores de acordo com o tipo de solo

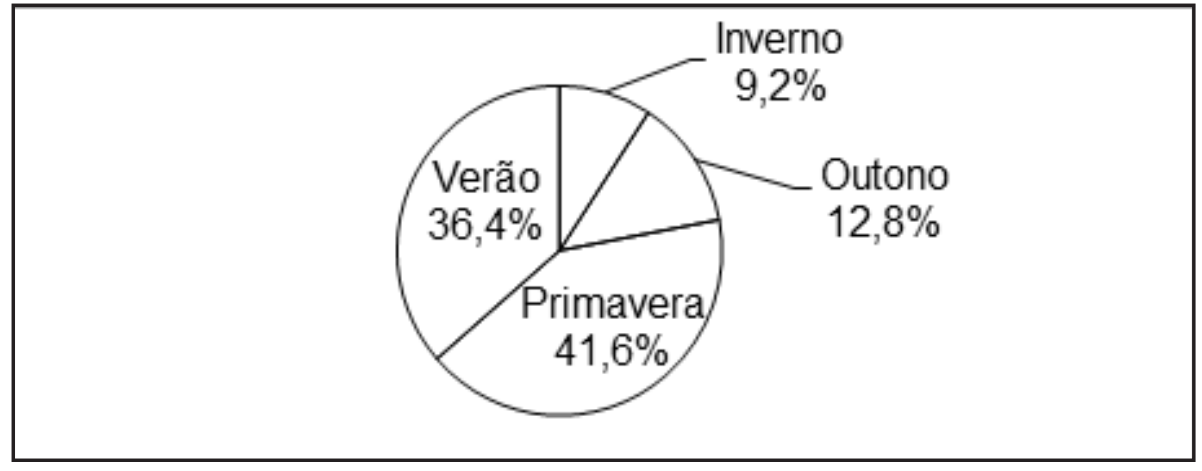

Figura 15 - Quedas de árvores por estação do ano

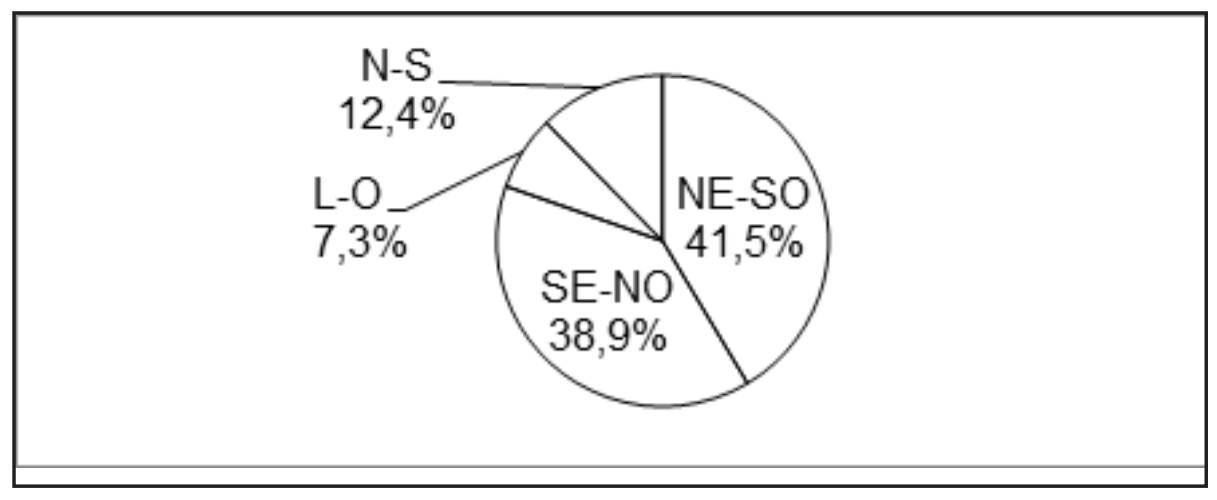

Figura 16 - Quedas de árvores por orientação da rua 


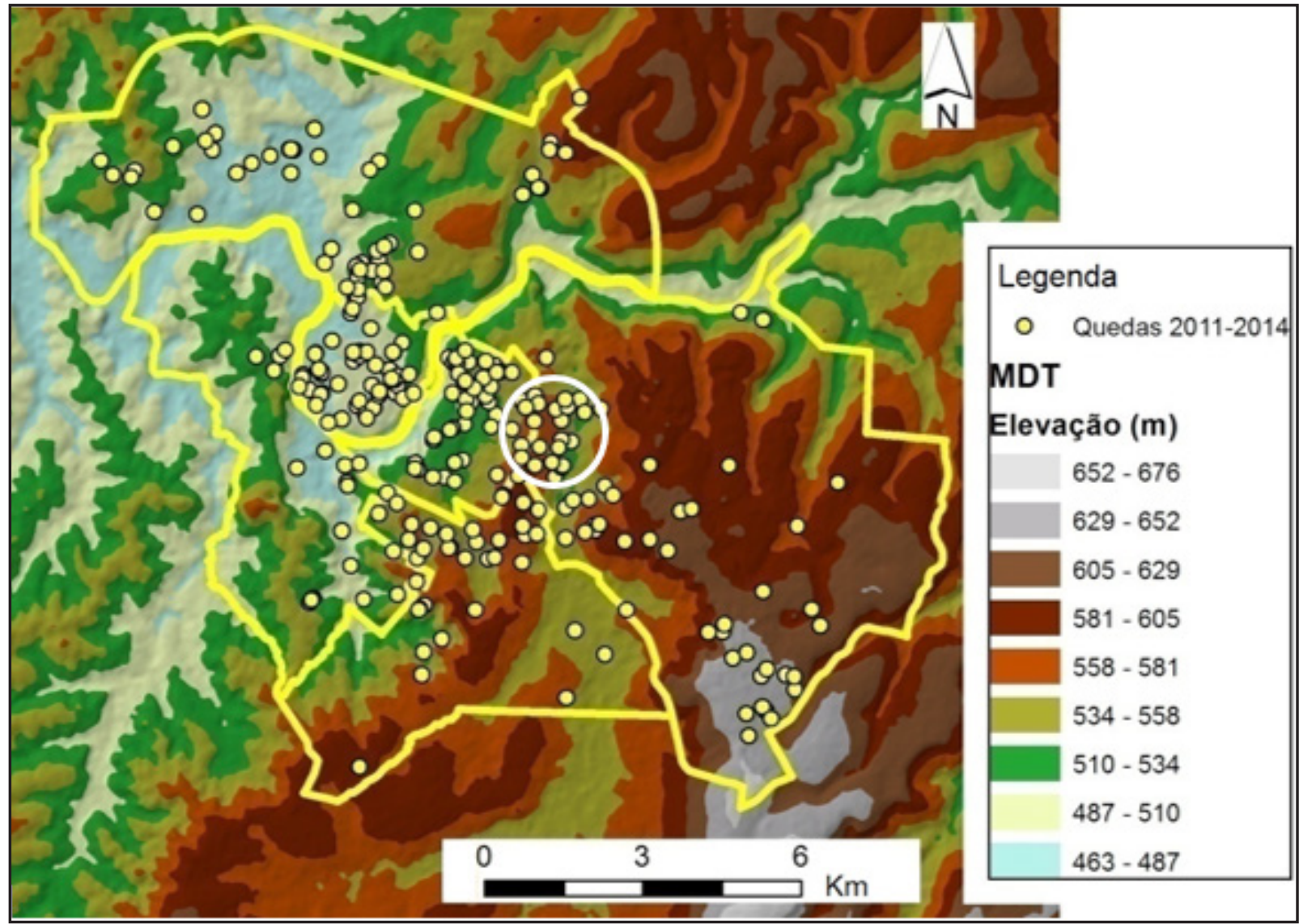

Figura 17 - Quedas de árvores conforme o modelo digital do terreno (MDT) de Piracicaba/SP; o círculo em branco compreende os bairros São Judas e São Dimas, em altitude elevada

\section{Vulnerabilidade de espécies}

Foram pressupostos 123 indivíduos, além de 4 mortas. Rollo (2014) amostrou 9,6\% dos 3759 quarteirões de Piracicaba, ou seja, 360, e encontrou 5744 indivíduos, numa população arbóreo-arbustiva estimada em 60.146 indivíduos de rua na cidade, pertencentes a 165 espécies.

Para ter representatividade nas pressuposições das quedas, considerou-se pelo menos 2 casos e comparou-os com os resultados de Rollo (2014), a fim de verificar se as que caem mais são porque há mais exemplares ou se, de fato, são mais vulneráveis. O índice foi obtido dividindo-se a quantidade de queda pressuposta pela quantidade existente nas ruas e transformada em porcentagem (Figura 18).

As espécies mais vulneráveis foram Pachira aquatica Aubl. (monguba), Handroanthus sp. (ipê roxo) e Tipuana tipu (Benth.) Kuntze (tipuana). Apesar da análise somente visual, as espécies Schizolobium parahyba (Vell.) S.F. Blake (guapuruvu) e Triplaris americana L. (pau formiga), raros em ruas, mas comuns em praças, costumam falhar no tronco, ao sofrer torção. Ambos os responsáveis pelas remoções das quedas, Bombeiros e SEDEMA, mostraram satisfatório grau de conhecimento no assunto, uma vez que representantes dos Bombeiros disseram que tipuana, sibipiruna e ipê caem bastante, enquanto que representantes da SEDEMA, ipê e ficus benjamina.

A figura 19 ressalta a importância do tamanho do canteiro, visto que, se o mesmo for estreito, as raízes tendem a subir para respirar e comprometem a sustentação, tornando-se vulneráveis à queda, conforme observado na Rua Pedro Eusébio Stocco, 362 (bairro Jardim Alvorada) e Rua dos Uirapurús, 133 (bairro Parque Chapadão), respectivamente.

\section{Conclusões}

A pesquisa teve como contribuição o entendimento das quedas de árvores no município de Piracicaba/SP, sendo o fator "urbanização" como um dos principais responsáveis, visto que $36,7 \%$ concentraram-se na região do centro, enquanto que $48,4 \%$, em solo classificado como urbanizado. Isso se deve em função de condições estressantes para as plantas, como solo compactado, canteiros estreitos e danificações no sistema radicular, capaz de comprometer a sustentação.

As estações do ano que mais caíram árvores foram primavera e verão que, juntas, somaram 78,0\% do total. 


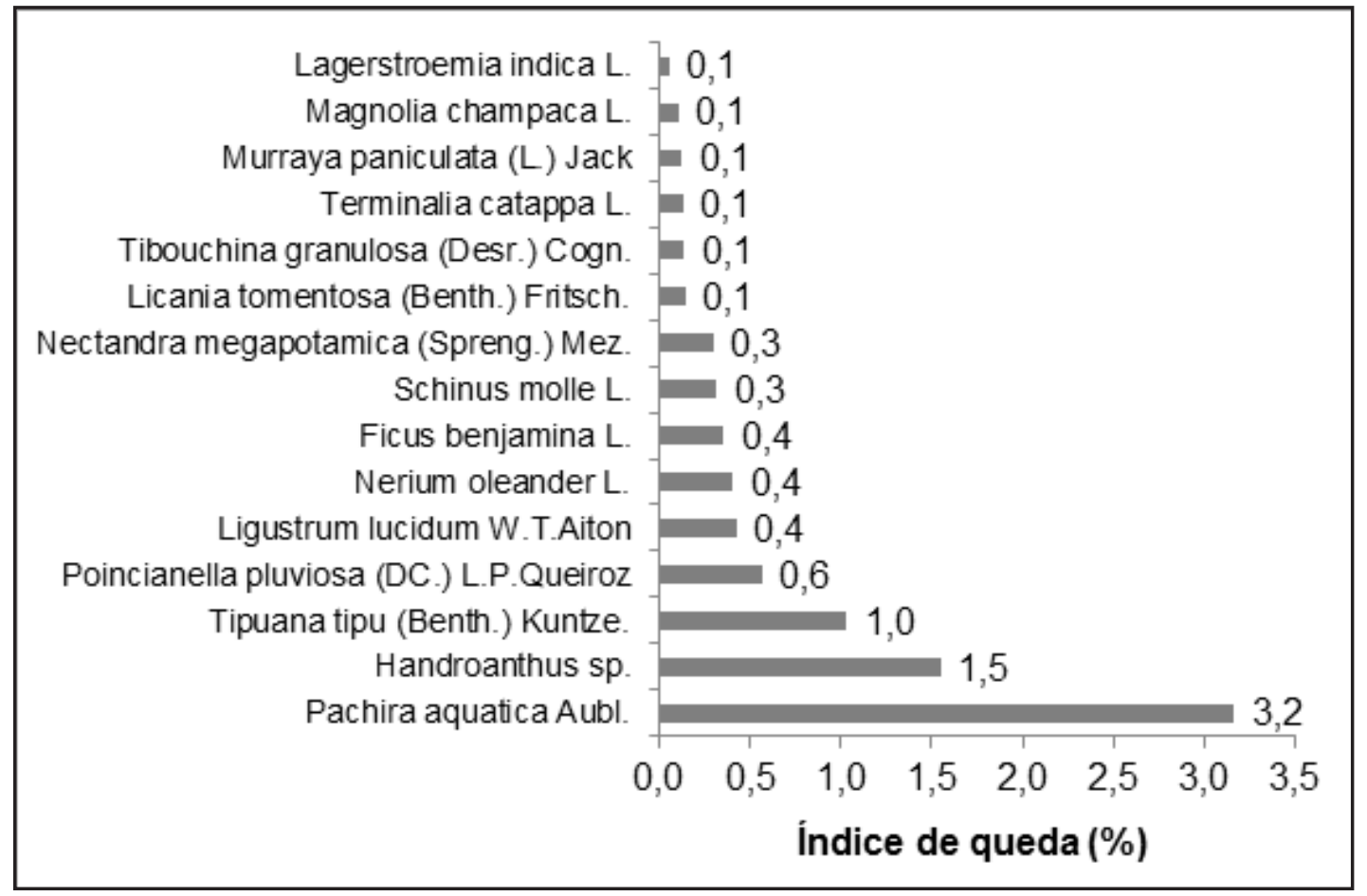

Figura 18 - Espécies plantadas na arborização de vias públicas vulneráveis à queda, conforme os 275 casos do banco de dados dos Bombeiros, durante 3,5 anos passados

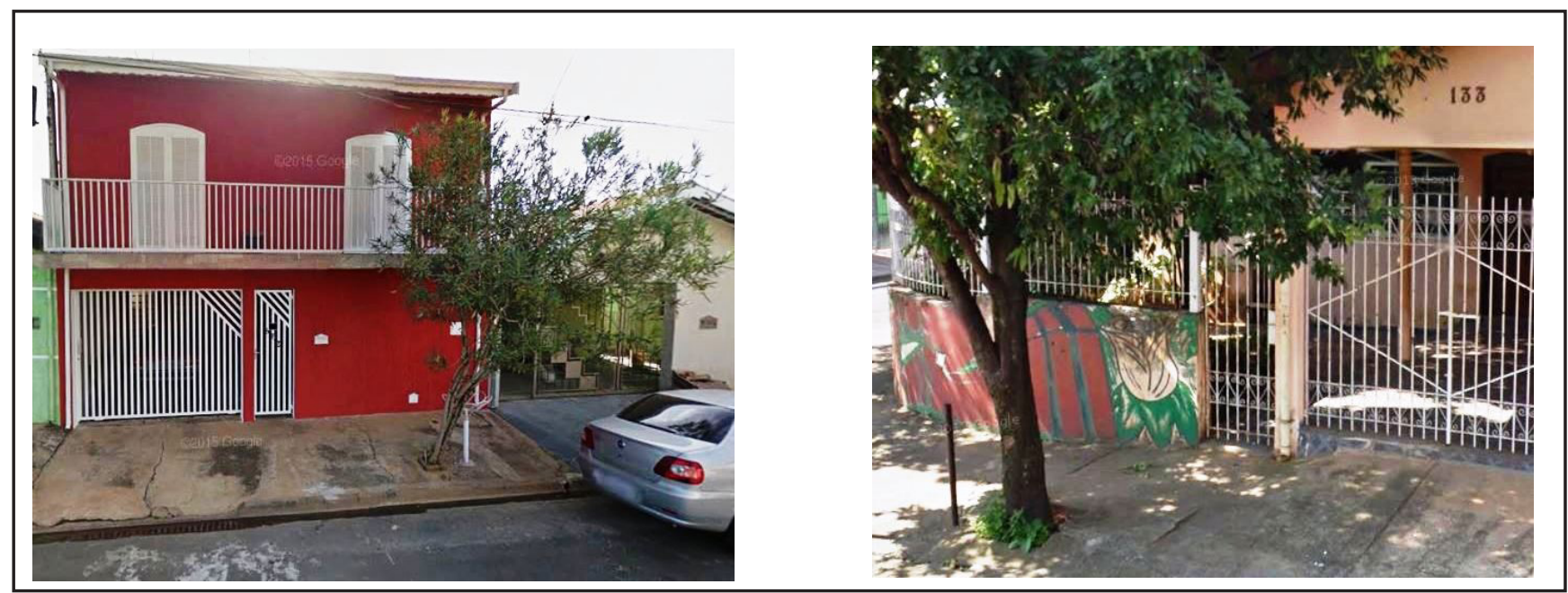

Figura 19 - Exemplos de plantas com canteiro de tamanho reduzido que caíram: Nerium oleander L. (espirradeira) e Licania tomentosa (Benth.) Fritsch. (oiti), nessa ordem

Exatamente nesse período que ocorrem os agravantes chuva (verão) e vento (primavera) e, dependendo das condições fitossanitárias, podem ocasionar a queda. Enquanto que $97,1 \%$ caíram com rajada de vento superior a $7 \mathrm{~m} \mathrm{~s}-1$ nas últimas 24 horas, conforme metodologia proposta por Oliveira e Lopes (2007), quase metade $(42,2 \%)$ sucumbiram com ventos superiores a $15 \mathrm{~m} \mathrm{~s}-1$. Do total, $65,5 \%$ das árvores caíram com chuvas nas últimas 24 horas.

O período de retorno esperado de ventos fortes, classificados entre "temporal" e "tornado/furacão", conforme a Escala de vento de Beaufort, com velocidade superior a $75 \mathrm{~km} \mathrm{h-1,} \mathrm{é} \mathrm{de} 1$ a cada 128,5 dias, ou seja, 2,8 eventos por ano, enquanto que ventos acima de $100 \mathrm{~km} \mathrm{~h}-1,1$ a cada 1087 dias (equivalente a 3 anos).

As espécies mais vulneráveis perante as condições analisadas foram Pachira aquatica Aubl. (monguba), Handroanthus sp. (ipê roxo) e Tipuana tipu (Benth.) Kuntze (tipuana), o que representa oportunidades de manejo específicas, cujas condições intrínsecas do local de plantio podem ser desfavoráveis.

Baseado na direção dos ventos predominantes de leste, sudeste e sul (ventos alísios), concluiu-se que os melhores lugares para localizar as indústrias são zona 
norte, noroeste e oeste, visto a importância da dispersão dos poluentes, evitando a entrada desses no interior das cidades.

\section{Referências}

ALBERS, J.S.; POKORNY, J.D.; JOHNSON, G.R. How to Detect and Assess Hazardous Defects in Trees. In: POKORNY, J.D. (Ed.). Urban Tree Risk Management: A Comunity Guide to Program Design and Implementation. St. Paul: USDA Forest Service. 1992. chap. 3. p. 41-116.

BONAN, G.G. Ecological Climatology: Concepts and Application. New York: Cambridge Univ. Press, 2002. 990p.

BURGARDT, S.; LEITE, M.L.; VIRGENS FILHO, J.S. Direção horária predominante e de rajada de vento em localidades dos campos gerais do Paraná e arredores. Revista Brasileira de Climatologia, Curitiba, v. 8, p. 137-151, 2011.

CAMARGO, R. Boletim Climatológico Anual da Estação Meteorológica do IAG / USP / Seção Técnica de Serviços Meteorológicos, São Paulo, v. 17, 2014. 76p.

CLEUGH, H.; GRIMMOND, S. Urban Climates and Global Climate Change. In: HENDERSON-SELLERS, A.; MCGUFFIE, K. The Future of the World's Climate, Oxford: Elsevier. 2011. chap. 3. p. 47-76.

DANCEY, C.; REIDY, J. Estatística Sem Matemática para Psicologia: Usando SPSS para Windows. 3.ed. Porto Alegre: Artmed, 2006. 608p.

DOBBERT, L.Y.; PRATA-SHIMOMURA, A.R.; MENDES, F.H.; SILVA FILHO, D.F. The influence of tree canopy cover on urban thermal comfort. In: CONGRESSO LUSO - BRASILEIRO PARA O PLANEAMENTO URBANO REGIONAL INTEGRADO E SUSTENTÁVEL, 6., 2014, Lisboa. Proceedings... Lisboa: PLURIS, 2014. 8p.

DOMINGUEZ, J.M.L.; BITTENCOURT, A.C.S.P.; MARTIN, L. Controls on Quaternary coastal evolution of the east-northeastern coast of Brazil: roles of sea-level history, trade winds and climate. Sedimentary Geology, Amsterdam, v. 80, n. 3-4, p. 213-232, 1992.

FIORAVANTI, C. Estufa que exporta poluição. Pesquisa FAPESP. 2002. p. 28-35.

MATTHECK, C. Updated Field Guide for Visual Tree Assessment. Karlsruhe: Forschungszentrum Karlsruhe Gm, 2007. 170p.
MATTHECK, C.; BRELOER, H. The body language of trees: a handbook for failure analysis. London: The Stationery Office, 1997. 239p.

MENDES, F.H.; SILVA FILHO, D.F.; LOPES, A.M.S. A sombra de edifícios como índice de verticalização das cidades. Hipótese, Itapetininga, v. 1, n. 1, p. 24-34, 2015.

OKE, T.R. Boundary layer climates. 2nd. ed. London: Routledge. 1987. 435p.

OLIVEIRA, J.B.; CAMARGO, M.N.; ROSSI, M.; CALDERANO FILHO, B. Mapa pedológico do Estado de São Paulo: legenda expandida. Campinas: Embrapa Solos / IAC, 1999. 64p.

OLIVEIRA, J.B.C.; PRADO, H. Carta pedológica semidetalhada do Estado de São Paulo: Folha Piracicaba. (SF 23-Y-A-IV). Campinas, Instituto Agronômico de Campinas, 1989. Mapa, escala 1:100.000.

OLIVEIRA, S.; LOPES, A.M.S. Metodologia de avaliação do risco de queda de árvores devido a ventos fortes. O caso de Lisboa. In: CONGRESSO DA GEOGRAFIA PORTUGUESA, 6., 2007. Lisboa. Anais... Lisboa: CGP, 2007. 21p.

OMM - ORGANIZAÇÃO METEOROLÓGICA MUNDIAL. Calculation of monthly and annual 30-year standard normals. WMO. WCDP, n. 10. Geneva, 1989. (Technical document, 341).

PRATA, A.R. Dimensionamento do impacto da altura de edifícios nas condições de ventilação natural do meio urbano simulando em túnel de vento: o caso de Santos. 2005. 243p. Tese (Doutorado em Arquitetura e Urbanismo) - Faculdade de Arquitetura e Urbanismo, Universidade de São Paulo, São Paulo, 2005.

RIBEIRO, P; LOPES, A. Modelação do risco de queda de árvores sobre as viaturas devido a ventos fortes em Lisboa. In: CONGRESSO DA GEOGRAFIA PORTUGUESA, 8., 2011. Lisboa. Anais... Lisboa: CGP, 2011. p. 1-6.

ROLLO, L.C.P. Metodologias de quantificação de áreas verdes urbanas: mapeamento da cobertura arbórea e inventário florestal de árvores de rua em cidades do Estado de São Paulo. 2014. 103p. Tese (Doutorado em Recursos Florestais) - Escola Superior de Agricultura "Luiz de Queiroz", Universidade de São Paulo, Piracicaba, 2014.

SANTOS, R.M. Morfologia urbana e conforto térmico. AUP 823 Seminário da Integração, Faculdade de Arquitetura e Urbanismo, 2004. 13p. 
SEITZ, R.A. Manual de poda de espécies arbóreas florestais. Curitiba: FUPEF, 1995. 56p.

SENE, E.; MOREIRA, J.C. Geografia geral e do Brasil: espaço geográfico e globalização. São Paulo: Scipione, 1998. 504p.

SHASHUA-BAR, L.; HOFFMAN, M.E. Vegetation as a climatic component in the design of an urban street: An empirical model for predicting the cooling effect of urban green areas with trees. Energy and Buildings, Lausanne, v. 31, n. 3, p. 221-235, Apr. 2000.

TROEN, I.; PETERSEN E.L. European Wind Atlas, Roskild: Risø National Laboratory, 1989. 656p. 